Nonobl ast i c sar coma of the ki dneys i $n$ an i nf ant I eukaemi a

\begin{tabular}{|c|c|}
\hline 著者 & I kawa Yasuhi ro, Sai kawa Yut aka \\
\hline $\begin{array}{l}\text { journal or } \\
\text { publ i cat } i \text { on } t i t l e\end{array}$ & Eur opean Jour nal of Haemat ol ogy \\
\hline vol une & 78 \\
\hline nunber & 2 \\
\hline page $r$ ange & $181-181$ \\
\hline year & 2007-02-01 \\
\hline URL & ht t p: //hdl . handl e. net /2297/6754 \\
\hline
\end{tabular}




\section{Monoblastic sarcoma of the kidneys in an infant leukaemia}

\section{Yasuhiro Ikawa, Yutaka Saikawa}

Department of Paediatrics, Kanazawa University Graduate School of Medical Science,

Kanazawa, Japan

Corresponding author: Yutaka Saikawa, M.D. \& Ph.D.

Department of Paediatrics, Kanazawa University Graduate School of Medical Science,

13-1 Takara-machi, Kanazawa 920-8641, Ishikawa, Japan

Tel: +81-76-265-2314; Fax: +81-76-262-1866; E-mail: saikawa@ped.m.kanazawa-u.ac.jp

Key word: monoblastic sarcoma, infant leukaemia, extramedullary tumour

Authors' disclosures of potential conflicts of interest: The authors declare no potential

conflicts of interest. All data contained herein are original and have not been published previously. 
An 8-month-old Japanese boy was diagnosed with acute monocytic leukaemia (AMoL, M5b according to $\mathrm{FAB}$ classifications) with $\mathrm{t}(9 ; 11)(\mathrm{p} 22 ; \mathrm{q} 23)$. Abdominal magnetic resonance imaging (MRI) demonstrated a homogeneous solid mass $(25 \times 36 \times 25 \mathrm{~mm})$ in the upper pole of the left kidney (panel A) and a cortical mass (diameter, $10 \mathrm{~mm}$ ) in the lower portion of the right kidney. Renal masses were hypointense relative to renal cortex on both T1- and T2-weighted imaging, with weak homogeneous gadolinium enhancement. Histopathological examination of cream-coloured biopsy sections revealed diffuse infiltration of cells surrounding intact glomeruli in the renal parenchyma (panel B). Predominant monoblastic features were shown on imprints (panel C). Fluorescence in situ hybridisation and Southern blot analyses identified the rearrangement of MLL gene, confirming a diagnosis of monoblastic sarcoma of the kidney. Monoblastic sarcoma is a less-common form of myeloid sarcoma, and may precede or occur concurrently with AMoL with 11q23/MLL rearrangements. Any part of the body can be involved, but renal involvement is rare and no infant cases have previously been reported. In cases such as the present, pathologically confirmed diagnosis is essential to establish appropriate therapeutic strategies, since the differential diagnosis could include primary renal tumours. 
Figure

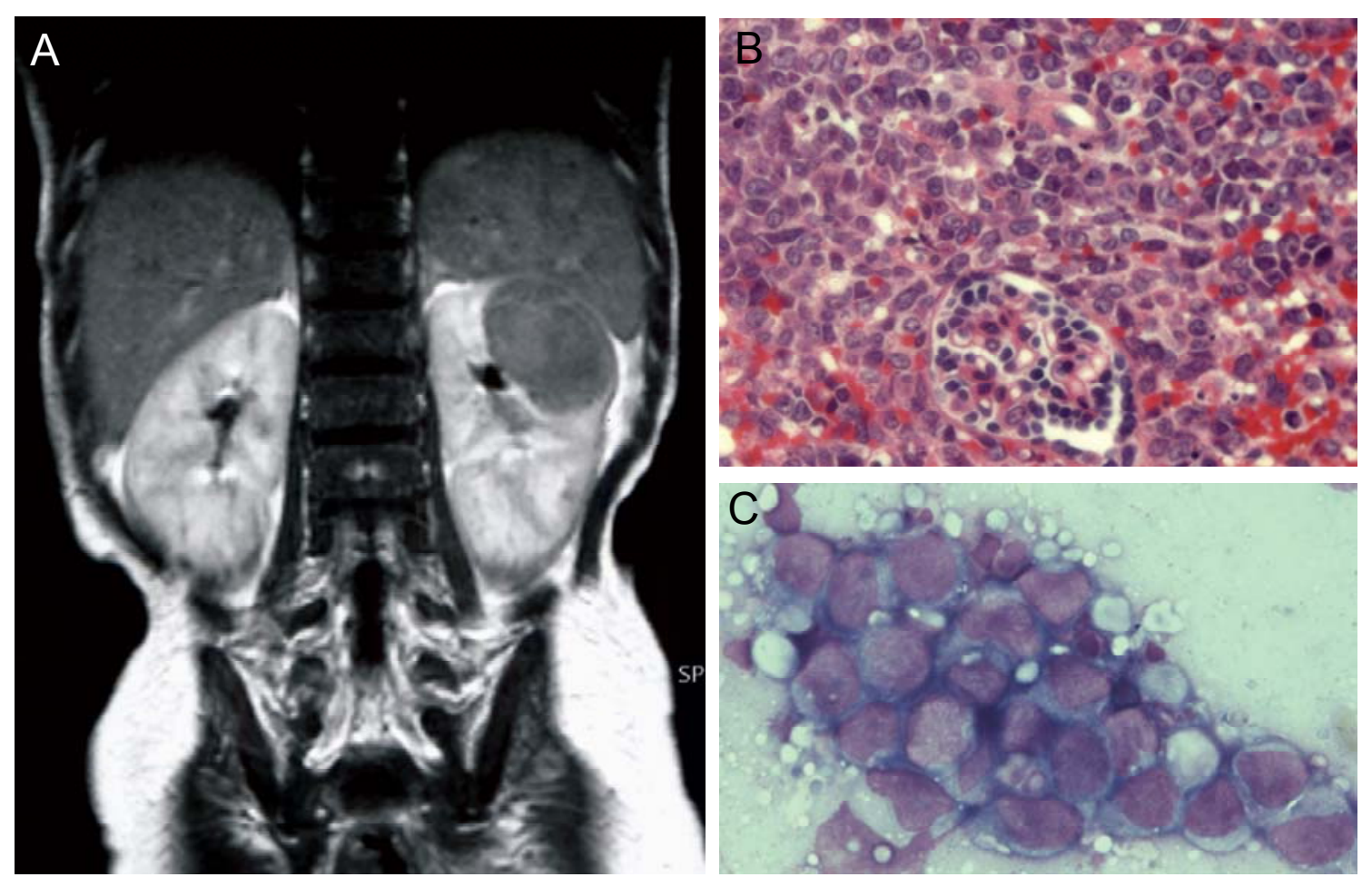

